\title{
What do empirical findings reveal about modelled energy demand and energy ratings? Comparisons of gas consumption across the English residential sector
}

\author{
A.J. Summerfield ${ }^{a}$, T. Oreszczyn ${ }^{a}$, J. Palmer ${ }^{b}$, I.G. Hamilton ${ }^{a}$, F.G.N. Li ${ }^{a}$, Crawley J. $^{\text {a }}$, R.J. Lowe ${ }^{a}$ \\ ${ }^{a}$ Bartlett School of Energy, Environment, and Resources, University College London, UK \\ ${ }^{\mathrm{b}}$ Cambridge Architectural Research \& Cambridge Energy
}

\section{Corresponding Author:}

Alex Summerfield, email: a.summerfield@ucl.ac.uk

Bartlett School of Energy, Environment, and Resources,

University College London, Central House, 14 Upper Woburn Place,

London WC1H ONN, UK

\section{Abstract}

Energy ratings and national housing energy models are useful for energy policy evaluation and development, but limited empirical validation of energy demand estimates is available across residential sub-sectors. This study used data from a sample of over 2.5 million gas-heated dwellings in England from the National Energy Efficiency Data-Framework (NEED) to compare with estimates of 2012 gas consumption from the Cambridge Housing Model (CHM), a national energy stock model. The analysis quantified differences by dwelling type, size, and age band. It also compared variations in gas consumption from NEED dwellings with that expected from Energy Performance Certificate (EPC) bands.

The findings show that the $\mathrm{CHM}$ overestimates average gas consumption from NEED for all dwelling types built before 1930, most notably for large detached dwellings. For other dwellings built since 1930, the model estimates were in relatively close agreement with NEED data. Furthermore, a simple comparison between estimated gas consumption and NEED data suggests savings from upgrading dwellings to at least EPC band C would be substantially lower than expected.

Findings raise question regarding assumptions used in models and EPC ratings, including occupancy and space heating patterns, and have implications for development of energy models and policy regarding energy efficiency programmes. 
Keywords: Energy demand; gas consumption; residential sector; national building energy models; Standard Assessment Procedure (SAP)

\section{Declaration of Interests}

$\mathrm{J}$ Palmer is a Director at Cambridge Architectural Research that developed the Cambridge Housing Model for the Department of Energy and Climate Change and which is used for modelling gas consumption in this paper. 


\section{Introduction}

In 2017 the UK government released the national Clean Growth Strategy (CGS) that underlines the importance of the residential sector as a priority target for energy policy as it accounts for over a fifth (22\%) of UK carbon emissions [BEIS 2017]. This part of the strategy is framed in terms of Energy Performance Certificates (EPCs), which are the UK's national energy labelling standard as part of the implementation of the EU Energy Performance of Buildings Directive and its successor legislation (EC 2003, EC 2010). The CGS proposes a retrofit programme that would upgrade as many dwellings as possible currently rated as EPC Band D or below to at least Band C by 2035 , including all fuel poor dwellings by 2030. (Table 1 provides a list and explanation of special terms and key acronyms used in this paper.)

The energy efficiency initiative outlined in the CGS provides an example of how policymakers combine or 'triangulate' the outputs of several distinct but related energy models and tools in the residential sector to help formulate policy and estimate potential energy and carbon savings. The first is the Standard Assessment Procedure (SAP) [DECC 2012], which in this or a simplified form - Reduced data SAP (RdSAP) - provides the basis in building physics and convention for generating energy ratings for EPC bands. Second, national housing energy models - typically relying on modified forms of the SAP method - are used to estimate energy demand across the residential stock as a whole or in key sub-sectors of interest, such as solid-walled dwellings. Third, empirical evidence on energy consumption and carbon emissions data are extracted from national statistics, such as the aggregated figures found in Digest of UKEnergy Statistics or findings generated from analysis of individual level dwelling data in the National Energy Efficiency Data-framework (NEED) [BEIS 2013]. Both of these sources are underpinned by reported meter data for gas and electricity from large-scale samples to generate estimates of annual energy consumption.

For the CGS, national energy statistics were used to show that although the number of homes has increased by about $25 \%$ since 1990 , total delivered and metered energy has remained essentially the same while carbon emissions have declined by around $20 \%$. These trends were then linked with indicators of energy efficiency improvement, for example, tightening of building regulations. While it should be noted that these effects may in part be confounded by large increases in fuel costs over the same period, separate analysis of NEED has identified savings from condensing boilers and cavity wall insulation (Hamilton et al. 2016). Regarding the proposed upgrading of dwellings to a minimum of EPC Band C, the CGS uses additional modelling not only to highlight the estimated energy cost 
savings for occupants, but also recognises that some potential savings may instead translate into health benefits, or cost savings for the National Health Service, due to reductions in the prevalence of cold and damp indoor conditions associated with these homes.

Table 1: Acronyms and specialist terms used in this paper.

\begin{tabular}{ll}
\hline $\begin{array}{l}\text { Acronym } \\
\text { or term }\end{array}$ & Meaning \\
\hline NEED & $\begin{array}{l}\text { National Energy Efficiency Data-Framework: Annualised gas and electricity } \\
\text { meter data linked to contextual data about the dwellings the meters are } \\
\text { monitoring. }\end{array}$ \\
CGS & $\begin{array}{l}\text { Clean Growth Strategy: the UK government strategy for reducing carbon } \\
\text { emissions to meet the UK Climate Change Act, published in 2017 } \\
\text { English Housing Survey: a rolling Government survey of the energy } \\
\text { characteristics and condition of English homes. }\end{array}$ \\
EPS & $\begin{array}{l}\text { Energy Performance Certificate: the energy labelling standard with energy } \\
\text { rating bands ranging from A (most efficient) to G (least efficient). }\end{array}$ \\
SAP & $\begin{array}{l}\text { Standard Assessment Procedure: a method for calculating EPCs that is the } \\
\text { basis of energy assessment in areas ranging from UK building codes to EPC } \\
\text { labels and national housing models. }\end{array}$ \\
RdSAP & $\begin{array}{l}\text { Reduced SAP: a simplified version of SAP that uses minimum set of inputs } \\
\text { and has default parameter settings where dwelling data are missing. }\end{array}$ \\
CHM & $\begin{array}{l}\text { Cambridge Housing Model: a national housing stock model developed for the } \\
\text { UK Government, which has been used historically to develop England's }\end{array}$ \\
Housing Energy Fact File. \\
Energy Consumption in the UK: national statistics on energy consumption, \\
such as for cooking and electrical appliances.
\end{tabular}

An issue implicit in this type of approach is that each of the models, such as the RdSAP for EPCs, have been developed with various assumptions relevant to their specific or original applications. The shared and unique assumptions across models are not necessarily clear to end-users, so it can become problematic to combine and interpret model outputs appropriately for policy development and evaluation. Complications continue to mount as models evolve over time with new versions and further adjustments to assumptions, such as the changes between SAP 2009 and SAP 2012. Furthermore, if the analyses focus on simple aggregated estimates of savings across the sector, then this may obscure systematic discrepancies in the predictions for specific sub-sectors, such as for older less efficient dwellings, and where the assumptions used in the models may have less validity.

Beyond the UK, the recent review by Copiello (2017) concluded that the mechanism and factors involved in the relationships between energy efficiency, modelled energy savings, and measured energy demand in the residential sector remain largely unresolved, with on-going implications for energy policy internationally. For instance, energy efficiency improvements that result in less than the expected savings maybe due to the rebound effect noted above (Sorrell 2015; Saunders 2015), whereby the benefits are taken by occupants in other ways, such as improvements in indoor 
temperatures. But such differences may also be accounted for by unforeseen technical factors, as exemplified by high heat losses in low energy homes being identified as due to unexpected convective pathways via party walls (Lowe et al. 2007). Sunikka-Blank and Galvin (2012) have examined datasets from various European countries and identified lower than expected energy consumption in less efficient dwellings. They have also shown that the size of the mismatch between the expected and delivered energy savings post retrofit differed substantially between dwellings in France and Germany (Galvin \& Sunikka-Blank 2016). Two other studies on a sample of dwellings in France (Laurent et al. 2013) and the Netherlands (Filippidou et al. 2018) have found that the ratio of actual to expected energy savings after retrofit - referred to as the heating factor - ranged from 40 to $60 \%$.

This study aims to advance understanding of the issues that arise in linking energy models and energy ratings based on SAP (or equivalent standard approaches used in Europe and elsewhere) with empirical evidence on energy consumption. The Background describes the key assumptions and parameter settings regarding dwelling characteristics and heating practices adopted in models. It then summarises evidence from recent studies on the gap between the expected and delivered energy savings after retrofit. The Methods section outlines the models, data sources, and analyses used. The Results section presents findings from the comparison of estimated gas consumption from two versions of a national housing model with empirical findings from a large sample of NEED dwellings in England categorised by type, age of construction, and size. It also compares gas consumption based on EPC Bands with corresponding empirical data and examines discrepancies between estimates of expected gas consumption savings in targeted sub-sectors of the residential stock that correspond with efficiency upgrades to EPC Band C (along the lines suggested in the CGS retrofit programme). In the Discussion and Conclusion sections, the observed pattern of differences are interpreted with some potential explanations, along with their implications for policy and future research priorities.

\section{Background}

\subsection{Standard assessment procedure and set heating patterns}

SAP is one of a family of National Calculation Methods defined under the Energy Performance of Buildings Directive. Though SAP predates this standard, its building physics core is compliant with BS EN ISO 13790 (2008). It was originally created to produce an energy label for a dwelling that would enable an occupant to compare the energy efficiency of one home against another, independent of location or occupant behaviour. It therefore assumes a standard occupancy pattern and specifies an 
internal demand temperature as part of its calculation, irrespective of the type or size of the dwelling. More precisely, the comparison is not energy efficiency but fuel costs, which can have a substantial impact on the SAP rating in cases where dwellings have similar energy efficiency but use gas rather than electricity or other more expensive fuels. (When the SAP methodology has been updated, as in 2012, it included adjustments to allow for relative changes in fuel prices over time.) The SAP calculation has been included in the regulatory process for new buildings, initially to test design compliance, and has subsequently been adopted to meet the European requirements for an EPC, i.e. displaying an energy rating label at the point of sale or rent of a property. The method has then been used for many applications outside of this narrow original intention.

It is worth noting that SAP was designed around a simple calculation method (one that originally had to be capable of being calculated manually when it could not be assumed computers sat on every designer's desk). It sought to model all of the significant factors that impacted the energy performance and therefore fuel costs of a dwelling, including the fact that buildings which were well insulated cooled down slower than ones that did not, but tried to do this without the complexity of a dynamic simulation model. Over time SAP has evolved and become more complex, for instance in using monthly rather than annual calculations for energy demand and in dealing with a variety of heating technologies. Much of the original detailed validation of the SAP algorithm was undertaken using results from new homes. In contrast, there has been little validation on existing dwellings, especially older dwellings, where the detailed construction and performance of the heating system is normally poorly known. Yet the majority of the application of SAP is now on these buildings built before the original introduction of SAP into the regulatory process, i.e. on the $90 \%$ of dwellings in England that predate the introduction of SAP into new build regulations.

The standard pattern of heating operation adopted in SAP is intended to provide typical households with a 'comfortable' internal environment [DECC 2014]. These indoor conditions are specified for what is defined as the living area or Zone 1 of the dwelling, with the resultant heating operation also applied to Zone 2 or the remaining indoor habitable area. So although Zone 2 is heated, it does not need to attain the same indoor conditions as Zone 1. SAP specifies that all dwellings have:

- demand temperature of $21^{\circ} \mathrm{C}$ for Zone 1 ;

- $\quad$ heating period of 9 hours per day on week days and 16 hours on weekends;

- total heating season of 8 months per year. 
Although the operational settings remain constant throughout the heating season, the total space heating requirements change according to the external conditions (based on a monthly calculation and the specified thermal properties of the dwelling).

\subsection{National housing energy models}

Variants of SAP or its precursor BREDEM [Shorrock \& Anderson 1995] have been used in national housing energy models to help develop domestic energy efficiency policies for more than two decades, including BREHomes [Shorrock \& Dunster 1997] and more recently the National Housing Model (NHM) and the Cambridge Housing Model (CHM) [Hughes et al. 2013]. In its full version, the CHM covers household energy demand across the residential stock in the UK and has underpinned data used in the Housing Energy Fact File (HEFF) [Palmer \& Cooper 2014] and Energy Consumption in the UK (ECUK) [DECC 2015].

In this study, estimates of gas consumption from two versions of the CHM are used with respect to the residential stock in England. The first variant of CHM in the analysis has SAP 2012 default settings and assumptions and is referred to as $\mathrm{CHM}(\mathrm{SAP})$. Previous findings from a comparative study of three bedroom dwellings suggested that an earlier version of the CHM tended to overestimate gas consumption slightly for most age bands, but particularly for pre-1919 dwellings (which are typically solid wall construction) compared with estimates from empirical data [Summerfield et al. 2015]. To improve model estimates overall, and specifically for solid wall dwellings, the CHM has been revised with two simple adjustments, referred to here as CHM Demand Temperature 19 or CHM(DT19):

- Demand temperature lowered to $19^{\circ} \mathrm{C}$ for SAP Zone 1 heated area [Hughes et al. 2013]

- U-value for solid walls is reduced from 2.1 to $1.4 \mathrm{~W} / \mathrm{m}^{2} \mathrm{~K}$ [Li et al 2015].

So this study uses the $\mathrm{CHM}(\mathrm{SAP})$ and $\mathrm{CHM}(\mathrm{DT} 19)$ to explore the patterns of differences of the estimates for 2012 gas consumption in England with the empirical findings from a large sample of dwellings obtained from NEED, disaggregated by dwelling type and construction age. It then examines the gas consumption indicated by EPC Bands with respect to NEED data to compare discrepancies in expected savings due to improving energy efficiency of dwellings to a minimum of EPC Band C.

\section{Methods}

This section outlines the process of generating model estimates for gas consumption from the CHM and EPC bands, which rely on inputs from the English Housing Survey (EHS) - such as floor, window 
and wall area estimates, construction type and boiler type - and then comparable empirical gas consumption data from the NEED. This study focused its investigation on four types of dwellings (detached, semi-detached, end terraces, and mid-terraces) that account for about $75 \%$ of dwellings in England. It does not include flats (i.e. apartments in multi-unit block) due to the variability in thermal characteristics of the building shell, and the complexity of heat flows in apartment buildings.

\subsection{The Models and Data Sources}

Cambridge Housing Model: The CHM is an open-access national-level stock model, which is constructed as a bottom-up building physics model based on SAP 2012 methodology that is applied to a dataset comprising 14,000 dwellings drawn from UK housing surveys, which provide a representative housing stock to model. It also includes energy use associated with electrical appliances and cooking, which are omitted from SAP ratings calculation: appliances energy use is calculated based on SAP Appendix L, and cooking energy use is based on BREDEM-8 [Anderson et al. 2002] with adjustments for heat gain related to cooking [Palmer \& Cooper 2014]. For this paper, which focuses on dwellings in England, the characteristics and dwelling weightings obtained from the EHS are used to calculate the contribution of each dwelling category to provide an overall estimates of gas consumption for various sub-sectors of the residential stock in England.

To reiterate, the distinction between the $\mathrm{CHM}(\mathrm{SAP})$ and $\mathrm{CHM}(\mathrm{DT} 19)$ relates to changes in the parameters used in the heating calculation: the $\mathrm{CHM}(\mathrm{DT} 19)$ formulation defines $19^{\circ} \mathrm{C}$ as the demand temperature for Zone 1 in all dwellings; the $\mathrm{U}$-value for solid walls is set to $1.4 \mathrm{~W} / \mathrm{m}^{2} \mathrm{~K}$; and the use of regional, year-specific climate data for external conditions. For this study, the external conditions are based on the weather correction for ECUK data in 2012 [BEIS 2016].

English Housing Survey (EHS): The EHS is a continuous national survey commissioned by the Department for Communities and Local Government (CLG 2014). The 2011-12 EHS collected information about people's housing circumstances and the condition and energy efficiency of housing in England.. In addition to weightings for the CHM dwellings, the 2011-12 EHS was used to obtain supporting data for:

- variation of household size with dwelling floor area;

- mean floor area for each dwelling type and age band category.

National Energy Efficiency Data-framework (NEED): the anonymised research dataset extracted from NEED has been prepared from individual (meter points) for gas and electricity consumption data, 
collected for BEIS sub-national energy consumption statistics. These were supplied with matched information on energy efficiency measures installed in dwellings, from the Homes Energy Efficiency Database and other sources. NEED 2012 annual gas consumption data based on meter readings have been weather corrected to standardised conditions for the annual period of 1 September 2011 to the 31 August 2012 (also known as the 2012 gas year). Records were linked to Valuation Office Agency (VOA) data that provide some information on basic physical characteristics, including size and dwelling type. The sample used in this study comprised over 2.5 million gas-heated dwellings (where this was specified as the main heating fuel) from the total of $\sim 4.1$ million dwellings in the prepared NEED research sample. Details about the variables used from NEED are given in Table 2. 
Table 2. Variables used in the analysis from NEED

\begin{tabular}{|c|c|c|}
\hline Variable & $\begin{array}{l}\text { Categories } \\
\text { (or rounding) }\end{array}$ & Comments \\
\hline $\begin{array}{l}\text { Gas } \\
\text { consumption }\end{array}$ & $\begin{array}{c}100-7,999 \\
\text { (nearest } 50 \mathrm{kWh} \text { ) } \\
8,000-15,999 \\
\text { (nearest } 100 \mathrm{kWh} \text { ) } \\
25,000-34,999 \\
\text { (nearest } 1,000 \mathrm{kWh} \text { ) } \\
35,000-50,000 \\
\text { (nearest } 5,000 \mathrm{kWh} \text { ) }\end{array}$ & $\begin{array}{l}\text { Annual gas consumption has different levels of } \\
\text { rounding applied but is treated as a continuous } \\
\text { variable. The data are based on gas meter } \\
\text { readings that have been weather corrected to } \\
\text { standardised conditions for the annual period of } 1 \\
\text { September } 2011 \text { to the } 31 \text { August } 2012 \text { (also } \\
\text { known as the } 2012 \text { gas year). In NEED, gas } \\
\text { consumption above } 50,000 \text { kWh is assumed to } \\
\text { not be residential and is omitted from the dataset. }\end{array}$ \\
\hline Dwelling type & $\begin{array}{l}\text { Detached } \\
\text { Semi-detached } \\
\text { End Terrace } \\
\text { Mid-terrace }\end{array}$ & $\begin{array}{l}\text { The analysis does not include "flats" (i.e. } \\
\text { apartments in a multi-unit block) due to the } \\
\text { variability in thermal characteristics of the building } \\
\text { shell, since in the number of external walls varies } \\
\text { according to the location of the unit within the } \\
\text { block. }\end{array}$ \\
\hline $\begin{array}{l}\text { Year of } \\
\text { construction }\end{array}$ & $\begin{array}{c}\text { Pre } 1930 \\
1930 \text { to } 1949 \\
1950 \text { to } 1966 \\
1967 \text { to } 1982 \\
1983 \text { to } 1995 \\
\text { Post } 1995\end{array}$ & $\begin{array}{l}\text { These broadly correspond to various building } \\
\text { construction eras in the UK, for instance the } \\
\text { majority of pre-1930 dwellings are solid wall, } \\
\text { rather than cavity wall construction. }\end{array}$ \\
\hline Floor area & $\begin{array}{l}1 \text { to } 50 \mathrm{~m}^{2} \\
51-100 \mathrm{~m}^{2} \\
101-150 \mathrm{~m}^{2} \\
\text { Over } 151 \mathrm{~m}^{2}\end{array}$ & $\begin{array}{l}\text { This refers to the accessible internal floor area of } \\
\text { the dwelling. }\end{array}$ \\
\hline EPC bands & $\begin{array}{l}\text { A or } B(S A P \geq 81) \\
C(80>S A P \geq 69) \\
D(68>S A P \geq 55) \\
E(54>S A P \geq 39) \\
F(38>S A P \geq 21) \\
\quad G(S A P \leq 20)\end{array}$ & $\begin{array}{l}\text { In NEED, the EPC Bands refer to energy ratings } \\
\text { or assessments of each dwelling based on SAP } \\
2009 \text { or RdSAP } 2009 \text {, as the }\end{array}$ \\
\hline
\end{tabular}

\subsection{Analysis}

NEED analysis: The NEED dataset was processed to select gas heated dwellings (and omitting flats) with valid gas consumption data for 2012 and descriptive statistics generated using SAS University Edition software. Due to the large sample sizes in the dwelling sub-sectors analysed in NEED, the resultant narrow $95 \%$ confidence intervals (typically of the order of $2 \%$ or $\pm 200 \mathrm{kWh}$ for annual gas consumption of $10,000 \mathrm{kWh}$ ) were not illustrated in the figures to maintain clarity, except for NEED gas consumption by EPC Band where they contributed meaningfully to the findings. It should be noted that $95 \%$ confidence intervals do not account for systematic bias and so do not reflect the overall uncertainty. 
EPC Band calculation: The range of gas consumption for primary and secondary heating and hot water corresponding to each EPC Band was calculated using a Microsoft Excel (V) model for SAP 2009 developed at UCL Energy Institute with standard parameter settings, including for UK external conditions, a demand temperature of $21^{\circ} \mathrm{C}$, and occupancy levels based on floor area. The mean floor areas were obtained from the EHS for each type and age band, with estimated gas consumption shown in (see Tables A1 and A2). Note that a key differences between SAP 2009 and SAP 2012, is that SAP 2009 used on a standard set of data for annual UK weather conditions [DECC SAP2009] whereas SAP 2012 shifted to a monthly calculation that uses monthly regional weather data. The SAP 2009 estimates were cross-checked and agreed closely with estimates of gas consumption obtained from CHM under the appropriate SAP settings and corresponding floor areas. EPC bands that estimate gas consumption above $50,000 \mathrm{KWh}$ are provided for interest only, since in the NEED dataset this value is set as a maximum for residential gas consumption, and few dwellings approach this level of consumption.

\section{Results}

\subsection{CHM and NEED comparison}

Figure 1 illustrates the modelled gas consumption from $\mathrm{CHM}(\mathrm{SAP})$ and $\mathrm{CHM}(\mathrm{DT} 19)$ and the mean gas consumption from the 2012 NEED dataset by dwelling type and age (with the data given in Table A3). Overall, NEED gas consumption results are lower across all dwelling types and age bands than the estimates from the $\mathrm{CHM}(\mathrm{SAP})$, whereas $\mathrm{CHM}(\mathrm{DT} 19)$ generally shows closer agreement except for older dwellings. The varying step jumps in predictions are an artefact of varying classifications for construction age bands, so the key issue is the overall trend or pattern in the observed deviations over time.

Comparison of estimates from the two CHM models in Figure 1a-d indicates that for all dwelling types since 1950, CHM(SAP) generates results in the range of $17-21 \%$ higher than $\mathrm{CHM}(\mathrm{DT} 19)$, but for pre1900 dwellings this progressively widens to $39 \%$ between models. The latter increase is largely due to the impact of more solid walled properties in older buildings (which reflects the lower U-value of $1.4 \mathrm{~W} / \mathrm{m}^{2} \mathrm{~K}$ used for these external walls in CHM(DT19). For post-1995 dwellings both versions of the CHM estimate increased gas demand even though these were built under tighter building regulations (in energy efficiency terms), probably due to the larger floor area than dwellings in slightly older age bands. 
Although considerably lower than $\mathrm{CHM}(\mathrm{SAP})$, the estimates from $\mathrm{CHM}(\mathrm{DT} 19)$ for detached dwellings are still higher than the mean gas consumption from NEED, and instead tend to agree with the $75^{\text {th }}$ percentile NEED data. For all other dwelling types built since 1930, CHM(DT19) shows a close match with NEED data, but for those built prior to 1930 the $\mathrm{CHM}$ (DT19) gas consumption again tends to be closer to the $75^{\text {th }}$ percentile rather than mean values. Since the NEED dataset has only one category for pre-1930 dwellings, the gas consumption should lie approximately in the middle of the values obtained from the CHM models for the two older age categories (the pre-1900 and 1900-1929 dwellings used in CHM have a similar prevalence in the stock).

The sizable jump in gas consumption when comparing 1900-1929 to pre-1900 for all dwelling types using $\mathrm{CHM}(\mathrm{DT} 19)$ model estimates reflects the high prevalence of solid wall construction in the oldest age band. Some change is also evident in NEED, with pre-1930 detached dwellings having the highest mean gas consumption across age bands, but still lower than that estimated by CHM(DT19). A separate analysis not shown in the figure, however, revealed that when the NEED pre-1930 group is split between those with cavity wall construction and 'other' (presumed to be mainly solid walls in this category) the difference is only about $8 \%(23,770 \mathrm{kWh}$ versus $21,950 \mathrm{kWh}$, respectively). So wall construction does not appear to account for the size of increased gas consumption estimated for pre1930 dwellings from the $\mathrm{CHM}(\mathrm{DT} 19)$ model.

$\mathrm{CHM(DT19)}$ shows a progressive decline in gas consumption from older to newer detached dwellings, until the 1983-89 age band, at which point from where gas consumption flattens out (and even a small increase in the 1990-95 group). The NEED data also shows a decline in older dwellings (from the relatively lower values) but only until 1949, while for detached dwellings built since 1950 the gas consumption is essentially the same. This is not exactly the case for other dwelling types, which have a steady but shallow decline in gas consumption across the age bands (from pre-1930 to post-1995). To understand the discrepancies further, Figure 2 shows estimates from CHM(DT19) with NEED gas consumption by floor area categories for detached and mid-terrace dwelling. In contrast to the relatively close estimates for detached dwellings of area $51-100 \mathrm{~m}^{2}$ and $101-150 \mathrm{~m}^{2}$, for large $\left(>150 \mathrm{~m}^{2}\right)$ detached dwellings - specifically those built before 1975 - the CHM(DT19) substantially overestimates gas demand (10-40\%). For mid-terraces where CHM estimates are also consistently high for pre-1930 dwellings (and even more so for the 101-150 $\mathrm{m}^{2}$ group), but underestimate gas demand for those built since 1975 . Thus the issue underlying the discrepancy is related to dwelling size, though perhaps not directly or solely as many confounding factors may play a role. 


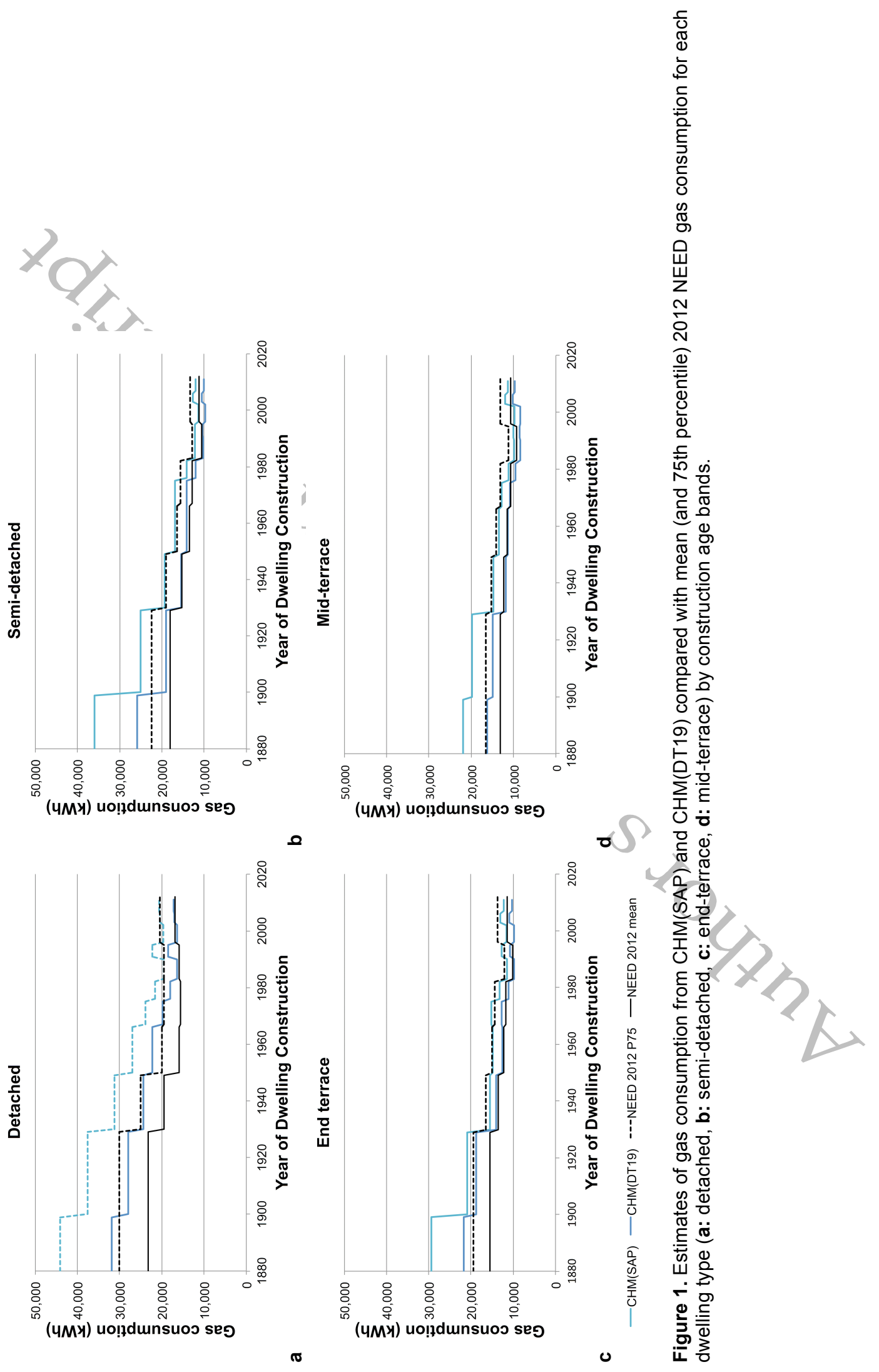



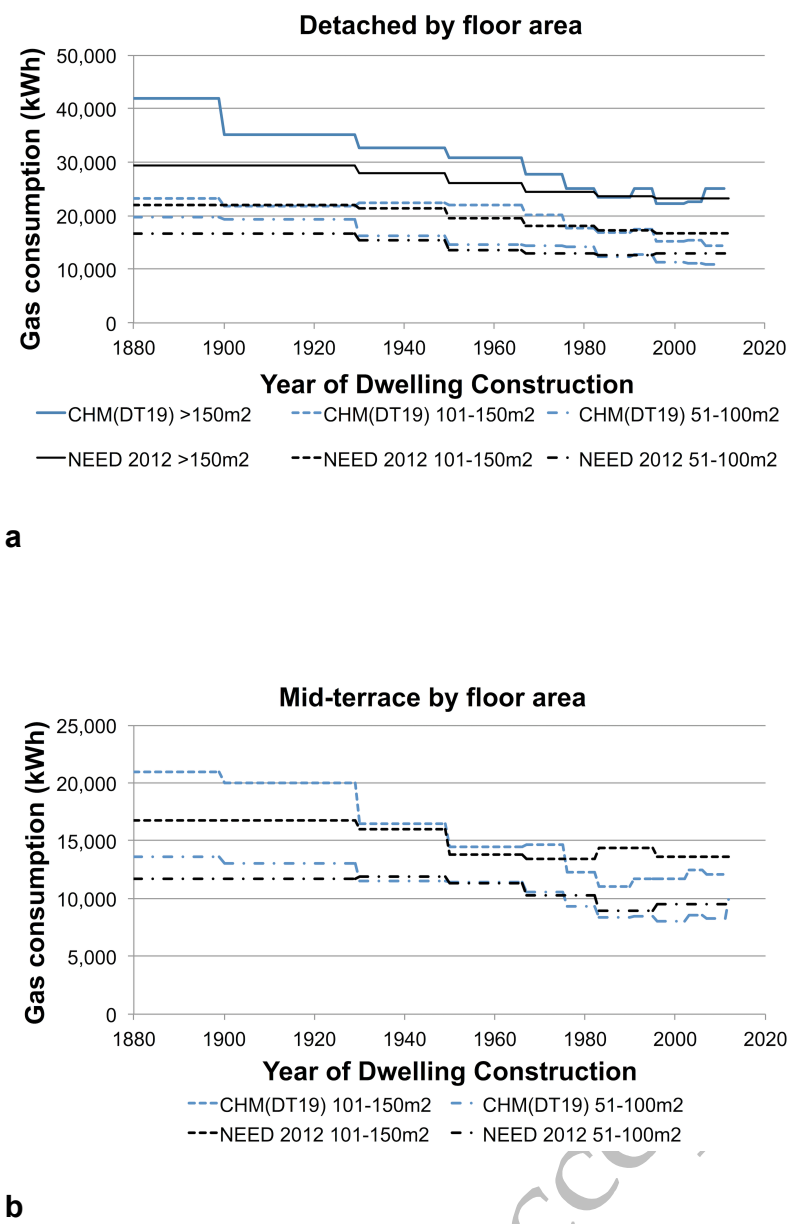

Figure 2. Mean 2012 gas consumption for (a) detached and (b) mid-terrace dwellings in NEED compared with CHM(DT19) by floor area bands. 


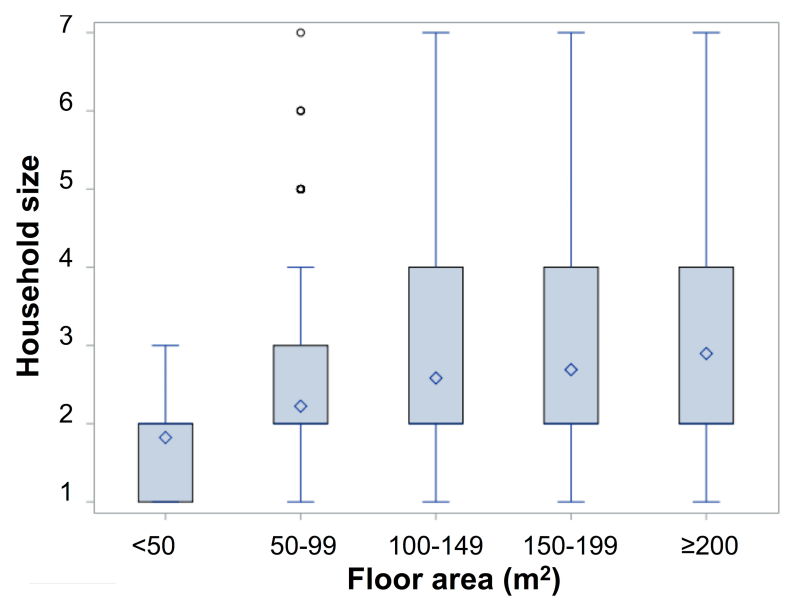

Figure 3. Box plot of household size (and showing the mean number of persons) by floor space categories for detached dwellings from 2012 EHS data.

One potential explanatory factor for the wide discrepancy seen in the CHM(DT19) estimates of gas demand for larger dwellings is suggested by findings from the EHS 2011-12 (Figure 3) that show the mean number of people in the household increases only slightly, from 2.6 to 2.9 , as the floor area increases from $100-150 \mathrm{~m}^{2}$ to $200 \mathrm{~m}^{2}$ and over for detached dwellings. This suggests that the level of occupancy, and hence the extent of space heating, scales more slowly with dwelling size than is assumed by the SAP algorithm. This is supported by previous research on mean indoor temperatures under winter conditions that has found older and larger dwellings in the UK tend to have lower mean temperatures than other dwellings (Hamilton et al. 2017).

\subsection{EPC bands and NEED gas consumption}

The findings above show considerable disagreement between the modelled data using standard policy models and the annualised metered data. The underlying causes of this are complex and so cannot easily be corrected for with model adjustments, other than noting older and larger properties in general use less energy than expected. This section seeks to investigate the impact these differences may have on specific policies when applied to a particular sub-sector of the population, using a current policy under development in the UK where as many as dwellings as possible should be retrofitted to EPC Band C standard or better by 2035. 
Figure 4 compares the annual gas consumption indicated by EPC bands calculated using SAP or RdSAP 2009 (Table S1) with the mean 2012 gas demand from corresponding EPC rated dwellings in NEED, disaggregated by type and age band. Note that where values are missing, especially for EPC Bands $E$ and $G$, the number of dwellings is insufficient $(N<50)$ to permit comparison. Overall the variation in NEED gas consumption is far less than that suggested by the EPC Band categories, and in almost all cases is within the range estimated for EPC Band C. Specifically, for NEED dwellings in EPC Bands A and B gas consumption is above that expected, while for those in EPC Bands D or below gas consumption is in most cases far lower than expected. The EPC Band estimates include secondary gas heating, whereas some NEED dwellings may use electricity for secondary heating and hence have lower gas consumption. If total electricity consumption is included in the NEED estimates, which includes appliances and is typically in the range between $3000-5000 \mathrm{kWh}$, this still is far lower than expected based on the EPC Bands. 


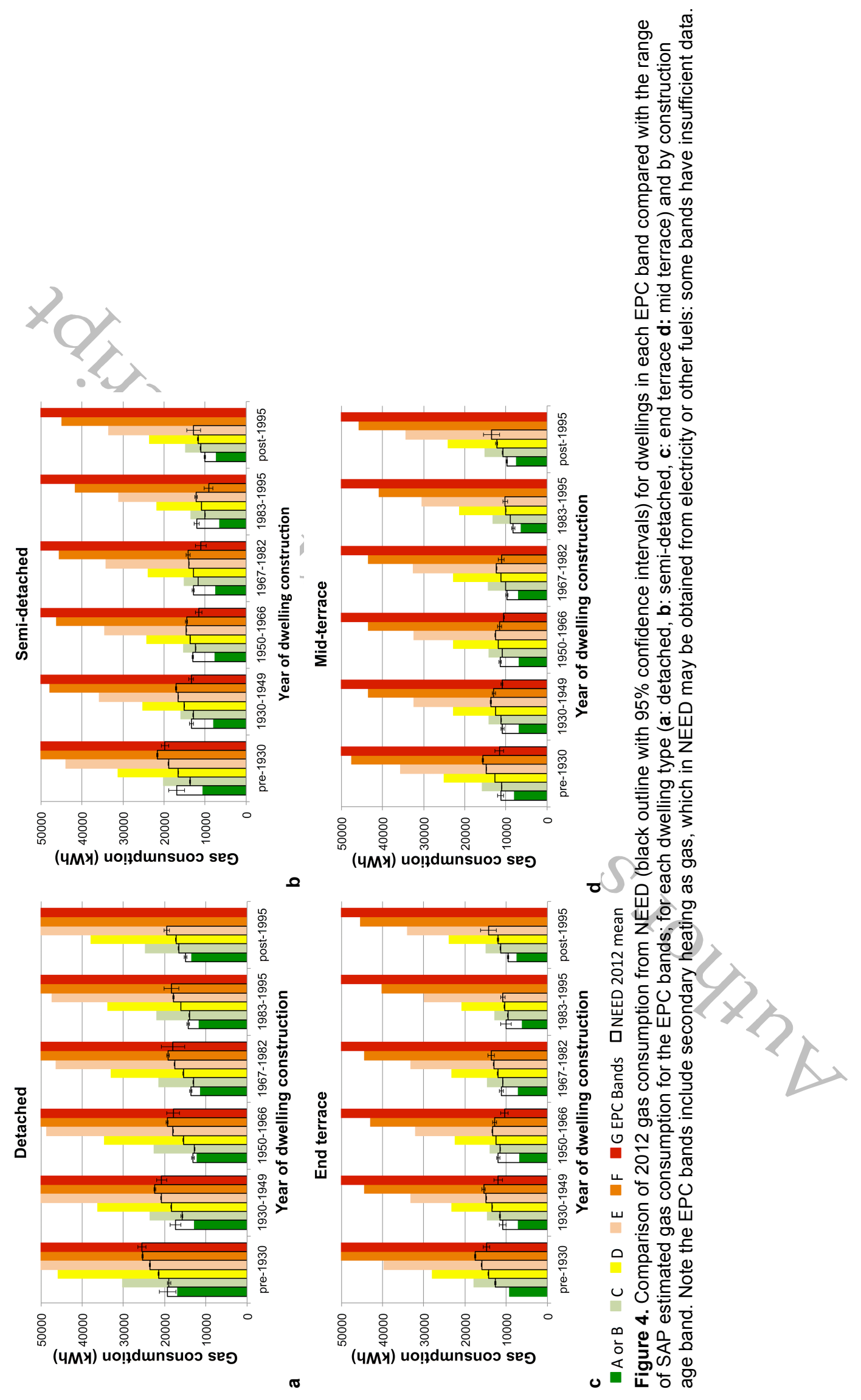




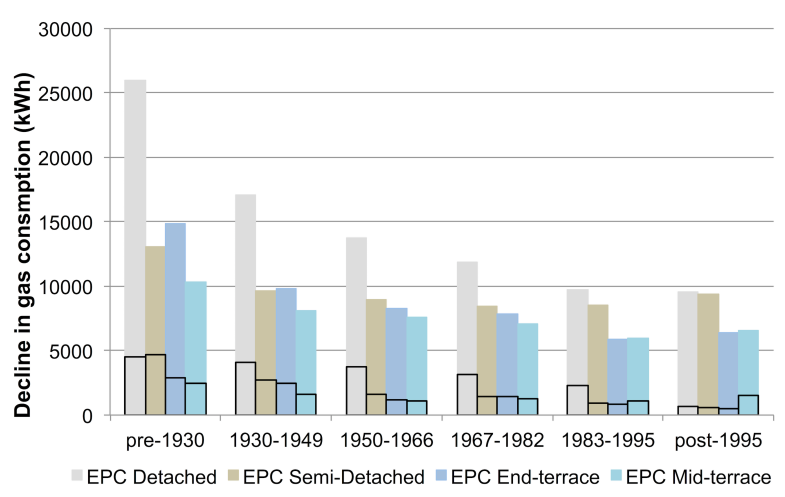

Figure 5. Comparison of the modelled mean decline in gas consumption from retrofitting dwellings up to EPC Band $C$ by age and dwelling type (shaded bars), with the equivalent estimate from NEED gas consumption data (indicated by the outline bars).

Figure 5 shows the energy saving expected from shifting all dwellings with EPC Band D or below up to EPC Band C in each dwelling age and type category, using gas demand calculated from the mean SAP 2009 rating for each EPC Band obtained from the EHS (Table A2). The equivalent savings calculated from NEED based on the weighted mean differences in gas consumption between EPC Bands are far less than expected, typically in the range of $20-30 \%$ and even lower for dwellings built since 1995. The savings from NEED dwellings are slightly higher if electricity is included (not shown), but not enough to substantively alter the large divergence in expected savings from the two estimates. It does suggest however that some secondary electric heating is occurring in the NEED dwellings.

\section{Discussion}

This study has examined disparities between the modelled and empirical estimates of gas consumption of English dwellings. Specifically, it used model estimates generated from three versions of the CHM, as an example of a SAP/EPC based national housing model, and matched them with the average empirically derived 2012 gas consumption obtained from NEED data. These comparisons, disaggregated by categories of dwelling age and type, have revealed both where the modelled and empirical gas consumption tend to agree, and where systematic differences occur. The results have highlighted the impact of standard assumptions, as is the case for SAP, for indoor heating operation across the dwelling stock. To place the implication of these findings in a policy context, the study has also compared simple 'face value' EPC based estimates of average energy savings if all dwellings in 
England were lifted to a minimum of EPC Band C (as recommended in the CGS), with an empirically based estimate of energy savings.

The first set of findings confirmed that the $\mathrm{CHM}(\mathrm{SAP})$, which uses the SAP setting of $21^{\circ} \mathrm{C}$ for demand temperature, substantially overestimates gas use for all four dwelling types and across all age bands, except those built since 1995. Furthermore, the discrepancy tends to widen markedly for older dwellings (built before 1930). This does not mean, however, that the demand temperature assumed in SAP is the reason for the discrepancy. As expected, CHM(DT19) with a lower demand temperature of $19^{\circ} \mathrm{C}$ setting and a U-value for solid walls reduced from 2.1 to $1.4 \mathrm{~W} / \mathrm{m}^{2} \mathrm{~K}$ (which specifically impacts older dwellings) generates gas demand estimates of $17-21 \%$ lower than $\mathrm{CHM}(\mathrm{SAP})$. This is similar to what would be expected, since a $2^{\circ} \mathrm{C}$ decline in demand temperature in the models (from 21 to $19^{\circ} \mathrm{C}$ ) will have a corresponding drop in the mean internal temperature across the dwelling, for instance a decline from $\sim 18^{\circ} \mathrm{C}$ to $\sim 16^{\circ} \mathrm{C}$. If the average external temperature over the heating season is about $6^{\circ} \mathrm{C}$, then the average temperature difference between internal and external conditions drops from $12^{\circ} \mathrm{C}$ to $10^{\circ} \mathrm{C}$, or by $\sim 17 \%$, with a corresponding decline in the average heat loss and hence gas demand. Furthermore, the lower U-values set for solid walls results in even larger expected drop in gas demand estimated for older dwellings.

CHM(DT19) suggests that a detached house built in 1880 might use twice as much gas as a detached house built in 2000 , whereas NEED shows that it typically uses only $40 \%$ more than a house built in 2000. If the empirical data suggests that gas consumption is much flatter between dwellings built at different times than the tools and models suggest, it could indicate that people living in older (and especially solid-wall) homes accept lower internal temperatures, on average. Alternatively, it may suggest that the heating systems in these older, larger homes are unable to reach desired temperatures within the periods householders use their heating - in contrast to more modern homes where set point temperatures are achieved relatively quickly. Yet, it is difficult to understand why external solid walls (even with a lower U-value assumed) should have such an significant impact on CHM estimates for gas demand for mid-terraces compared with 1930 terraces, since the area of external walls is relatively small and other attributes of the dwelling are likely to be largely the same. Closer investigation revealed that almost all the discrepancy for the detached dwellings was in the larger dwellings (over $150 \mathrm{~m}^{2}$ ), while predictions for the 50-100 $\mathrm{m}^{2}$ dwellings were below that of NEED values. The contribution of large dwellings to the overall estimate of average gas consumption is far greater for the detached, than is the case for other dwelling types. 
Overall, the findings suggest that other factors are at work that are contrary to model assumptions and are a particular issue for larger dwellings. The relationship between gas demand and floor area appears to be the crux of the issue. The operational settings used in the CHM are uniform for all dwellings (as per SAP), but NEED data suggests that with increased floor area, this assumption of a standard operation is not valid. Indirect evidence presented from the 2012 EHS supports this position, wher savings from upgrading dwellings eby the increase in average number of household members flattens out with floor area to only about 3 people for homes over $200 \mathrm{~m}^{2}$. This suggests that larger homes are likely to have qualitatively different heating patterns than smaller homes, and this is likely to be particularly the case for colder and older dwellings. For instance, it is feasible for parts of a large dwellings occupied by only two or three people to be effectively closed off from the rest of the accommodation. Secondly evidence from studies of indoor temperature in living areas and the main bedroom, suggest that older or larger dwellings have lower indoor temperatures than other dwelling groups [Hamilton et al. 2017a]. Although limited by sample size and availability of other evidence from other studies have also highlighted variations in the standard heating patterns assumed in SAP (Huebner et al. 2014, Hughes et al. 2016). It is also the case that the potential role of fuels other than electricity or gas, such as biomass, for secondary heating in these larger dwellings not been eliminated. Though to match the EPC estimates they would have been identified as the source for primary heating due to the scale is use required, rather than gas as specified for this sample.

The issue is that while clearly there needs to be an explicit shift away from the assumption of a standard heating operation across the dwelling stock, there is not sufficient evidence to say that this should just be met with a posteriori adjustment, for instance in the assumptions for demand temperature and the thermal properties of solid walls applied to some groups of dwellings. In addition to demand temperature, the difference between the modelled estimates and the empirical data could be accounted by a numerous factors including:

- variations in the heated floor area (and even some new unheated zones);

- variations in ventilation rates;

- $\quad$ variations in real U values;

- the effectiveness of heating systems;

- other socio-technical responses by occupants to keep energy costs low for larger older dwellings, such as single room heating; 
- use of fuels other than gas or electricity.

From the perspective of modelling, the demand temperature settings assumed in the model act as a proxy potentially obscuring the role of these other factors that impact the gas usage of the dwelling. Implications for framing policy initiatives: the comparison of NEED dwellings according to their EPC rating revealed a consistent pattern for mean gas consumption that was higher than expected for Band $\mathrm{A}$, within the range for Band $\mathrm{C}$, and much lower than expected for Band $\mathrm{D}$ or below. Again, it should be noted that here the EPC Band limits were calculated for all space and hot water heating from gas, including secondary heating, whereas the NEED data includes some dwellings that would have used electricity for some secondary heating. However the magnitude of electricity consumption in NEED dwellings (typically between 3000-5000 kWh, which includes appliances) indicates that any secondary electric heating is insufficient to account for the discrepancies. It is also possible that some dwellings used solid fuels (such as coal or biomass) for secondary heating, but this information and consumption is not recorded in NEED. Overall the empirical data showed far less variation in gas consumption than implied by EPC Bands, and in almost all age and dwelling type categories the empirical energy consumptions for all bands were within the nominal range for Band C. Given the earlier evidence from the $\mathrm{CHM}(\mathrm{SAP})$ and even allowing for a degree of inaccuracy in the assignment of EPC Bands, which would tend to dilute any differences, as well as other caveats raised here, the NEED results strongly suggest that the gas consumption for energy inefficient dwellings are substantially and systematically overestimated.

The evaluation of an upgrade programme that aimed to retrofit all dwellings in EPC Band D or below up to Band $\mathrm{C}$ also indicated that the reduction in gas demand could be far lower than expected if residents took the benefits as increased space heating, either in terms of temperature or the heated floor area. The results across most dwelling type and age bands suggested savings between $20-30 \%$ of that expected, but with older detached dwellings offering the most in terms of absolute energy savings. This effect has also been shown using the NEED energy data, where the savings associated with many improvements were below that estimated by models [Hamilton et al 2016, Hamilton et al 2017b]. In addition, this pattern across EPC bands is consistent with that found by Majcen et al. (2015) for dwellings in the Netherlands where there were increasing discrepancies between the expected and measured annual gas consumption for dwellings in lower energy rated categories.

Given that the NEED data suggests the average dwelling across all of the EPC bands is already using gas as if it were in EPC Band C range, it is not surprising that savings estimated from empirical data 
are relatively small. Furthermore, this also would question the adoption of a higher EPC Band B as the energy efficiency target as a way to obtain larger reductions in gas demand.

Yet the evidence does not necessarily mean an energy upgrade policy is not worthwhile. As the CGS notes, other benefits - such as improvements in indoor temperatures - would still occur in addition to any gas savings. Moreover, the lower the estimate of savings in gas consumption, the higher estimates of such co-benefits are likely to be. Prior to these results on EPC Bands, however, it was possible to argue that although SAP based estimates of energy demand are known to be systematically high, they might still be used to estimate the decline in energy demand with energy efficiency improvements. The evidence here suggests that this is not the case.

While this study has considerable methodological strengths, there are a number of caveats. The dataset analysed here is a sub-sample of the much larger full NEED dataset that was itself generated (stratified random sample) to match the broad characteristics of the residential stock using statistics from the EHS. The original NEED database, which has already been the subject of several research studies (e.g. Hamilton et al. 2016), was collected as occupants installed or received energy efficiency measures (new boiler, insulation) and so - despite the sample size - is not a strict random sample of the residential stock. The 2012 gas consumption data in NEED are temperature-adjusted to a ten year standard external conditions for different regional 'gas sectors' and annualised to a September 2011 to August 2012 'gas' year, rather than a calendar year which applies to electricity demand. It seems unlikely, however that these aspects will have introduced differences in a way that substantively alters qualitative message of the findings. It is worth noting that the NEED gas consumption data has continued to decline since 2012, potentially in response to economic factors and energy costs, and the discrepancy in gas consumption identified here is likely to have increased over time. The analysis has also not fully addressed the issue of gas used for hot water consumption and for cooking, which has been aggregated into the gas consumption data on the basis that their impact is unlikely to be of sufficient impact to alter the conclusions in a substantive way. Their inclusion does add considerably to the comparison - for instance EPCs do not include gas cooking whereas NEED(SAP) does. Last, the EPC bands analysis is based on SAP 2009, in comparison with 2012 data. Current EPCs use RdSAP and SAP 2012 settings, that among other changes use regional monthly temperature data, which would affect the EPC gas consumption estimates and hence the quantitative results if not their qualitative interpretation. Again, this is unlikely to alter qualitatively any of the key points identified in the study. 


\section{Conclusions and Policy Implications}

The results have highlighted a series of issues in using EPCs and national building energy models that apply standard operational parameters (heating patterns) across the building stock, especially where these result in broad systematic differences in estimated gas consumption and large discrepancies for certain key dwelling types and age bands, such as large older dwellings and detached dwellings.

Furthermore, the empirical evidence shows far less decline in gas consumption across age bands than expected from EPCs or the CHM, even where the parameters of $\mathrm{CHM}(19 \mathrm{DT})$ have been adjusted from the SAP assumptions to more closely reflect measured demand temperatures and $U$-values of solid wall dwellings.

An example of the implications of these differences were seen in the far lower estimated savings from NEED in gas consumption (as a proxy for space heating) from upgrading the stock to a minimum of EPC Band C. This does not mean such a policy initiative is not worthwhile, since as the CGS points out co-benefits may occur beyond energy savings, such as improved indoor conditions and consequent health benefits for vulnerable occupants. It does however highlight the need for care in using EPCs, which have been designed around standard operating assumptions to assist with comparisons between dwellings, are scaled as a tool across the national residential stock and where the empirical evidence on space heating just not appear to support uniform heating patterns. Estimates of the cumulative quantitative savings from energy efficiency measures applied in order to reach a minimum standard need to be assigned with a high degree of uncertainty, especially in their contributions to national carbon emissions targets, until a better understanding is reached of the sociotechnical factors at work in explaining current energy demand.

For energy ratings and national housing energy models to be fully useful as a tool to develop and evaluate proposed policy initiatives, operational settings (heating regimes) should be as close to empirically based as possible. This should not mean further adjustments of overarching parameters that impact heat loss used the national energy models, such as changes in the CHM demand temperature setting applied just to older larger dwellings, without clear empirical evidence to support such changes. This requires detailed studies that combine detailed occupant and dwelling surveys, with smart energy metering, monitoring of indoor conditions, and measurement of in situ U-values to understand variations in the operational heating patterns and heated floor area. One key question that needs to be investigated concerns the technical and socio-technical issues at work that leads to gas consumption across the NEED dwelling being around the level of EPC band C, with dwellings that 
have better EPC ratings tending to have higher gas consumption than expected, and those with lower ratings tending to have lower consumption than expected.

In the longer term, a move to energy labels not based only on modelled demand performance for uniform operation but actual consumption data using smart meter data to improve our understanding of energy demand across sub-sectors of the stock would strengthen the evidence base for energy policy development.

\section{Acknowledgements}

The Cambridge Housing Model was developed by Cambridge Architectural Research for DECC for the UK Government's Department of Energy and Climate Change, with support from Loughborough University and Cambridge Econometrics. Sofiane Hassen from Mines ParisTech carried out some of the CHM modelling supporting this paper.

Funding:

Contributions from authors Summerfield, Hamilton, Lowe, Oreszczyn and Crawley were undertaken with funding from the RCUK Centre for Energy Epidemiology (EPSRC Reference EP/K011839/1) and the Centre for Research in Energy Demand Solutions (EPSRC Reference EP/R035288/1).

\section{References}

Anderson, B. R., Chapman, P. F., Cutland, N. G., Dickson, C. M., Doran, S. M., Henderson, G., Henderson, J. H., Iles, P. J., Kosima, L., Shorrock, L. D., 2002. BREDEM-8 Model Description (2001 Update). Building Research Establishment (BRE), Garston, UK.

BEIS, 2017. Clean Growth Strategy: Leading the way to a low carbon future. London: Department for Business, Energy \& Industrial Strategy (BEIS) Retrieved from https://www.gov.uk/government/ publications/clean-growth-strategy

BEIS, 2013. National Energy Efficiency Data Framework, Department for Business, Energy and Industrial Strategy. Retrieved from https://www.gov.uk/government/collections/national-energyefficiency-data-need-framework

BEIS, 2016. Sub-national Consumption Statistics: Methodology and guidance booklet. London: Department for Business, Energy and Industrial Strategy. Retrieved from https://www.gov.uk/government/uploads/system/uploads/attachment_data/file/ 579258/Subnational_Methology_and_Guidance_Booklet_2016.pdf.

BS EN ISO 13790, 2008. Energy performance of buildings - Calculation of energy use for space heating and cooling, London: BSI.

Copiello S., 2017. Building energy efficiency: A research branch made of paradoxes Renewable and Sustainable Energy Reviews 69 (2017) 1064-1076 
Department for Communities and Local Government, 2014. English Housing Survey HOMES 2012. July 2014, London. DCLG.

Department of Energy \& Climate Change (DECC). 2010. SAP 2009: The Government's Standard Assessment Procedure for Energy Rating of Dwellings. 2009 edition, revised October 2010. Watford: Building Research Establishment.

DECC, 2014. SAP 2012: The Government's Standard Assessment Procedure for Energy Rating of Dwellings. 2012 edition, revised June 2014. Watford: Building Research Establishment.

DECC, 2015. Energy Consumption in the UK (ECUK) Domestic data tables 2015 Update. London: DECC.

Elwell CA, Biddulph P, Lowe RJ, Oreszczyn T., 2015. Determining the impact of regulatory policy on UK gas use using Bayesian analysis on publicly available data. Energy Policy, 86, 770-783.

European Commission, 2003. Directive 2002/91/EC of the European Parliament and of the Council of 16 December 2002 on the energy performance of buildings, Official Journal of the European Communities, 2003, OJL 001, 04/01/2003, 65-71

European Commission, 2010. Directive 2010/31/EU of the European Parliament and of the Council of 19 May 2010 on the energy performance of buildings (recast), Official Journal of the European Communities, OJL 153, 18.6.2010, 13-35

Filippidou F., Nieboer N., Visscher H., 2018. Effectiveness of energy renovations: a reassessment based on actual consumption savings. Energy Efficiency. doi: 10.1007/s12053-018-9634-8

Galvin R., Sunnikka-Blank M., 2016. Quantification of (p)rebound effects in retrofit policies - Why does it matter? Energy 95:415-424.

Hamilton, I. G., Summerfield, A. J., Shipworth, D., Steadman, J. P., Oreszczyn, T., \& Lowe, R. J. 2016. Energy efficiency uptake and energy savings in English houses: a cohort study. Energy and Buildings, 118, 259-276. https://doi.org/10.1016/j.enbuild.2016.02.024

Hamilton IG, O'Sullivan A, Huebner G, Oreszczyn T, Shipworth D., Summerfield A., Davies. M (2017a) Old and cold? Findings on the determinants of indoor temperatures in English dwellings during cold conditions Energy and Buildings 141: 142-157.

Hamilton, I., Summerfield, A., Oreszczyn, T., \& Ruyssevelt, P. 2017b) Using epidemiological methods in energy and buildings research to achieve carbon emission targets. Energy and Buildings, 154, 188197. https://doi.org/10.1016/j.enbuild.2017.08.079

Huebner G.M., McMichaelM, Shipworth D, Shipworth M, Durand-Daubin M, Summerfield A.J. 2014 The shape of warmth: temperature profiles in living rooms. Building Research and Information 43(2): 185-196.

Hughes M, Palmer J, Pope P., 2013. A Guide to the Cambridge Housing Model v3.0. London/Cambridge: DECC/Cambridge Architectural Research.

Hughes M, Pope P, Palmer J, Armitage P., 2016. UK Housing Stock Models Using SAP: The Case for Heating Regime Change. Science Journal of Energy Engineering. 4(2):12-22. doi: 10.11648/j.sjee.20160402.11

Laurent, M. H., Allibe, B., Tigchelaar, T., Oreszczyn, T., Hamilton, I. G., \& Galvin, R., 2013. Back to reality: How domestic energy efficiency policies in four European countries can be improved by using empirical data instead of normative calculations. In ECEEE 2013 Summer Study: Rethink, Renew, Restart. Sweden, pp.2057-2070.

Li F.G.N., Smith A.Z.P., Biddulph P., Hamilton I.G., Lowe R., Mavrogianni A., Oikonomou E., Raslan R., Stamp S., Stone A., Summerfield A.J., Veitch D., Gori V., Oreszczyn T., 2015. Solid-wall U-values: heat flux measurements compared with standard assumptions, Build. Res. Inf. 43 238-252. doi:10.1080/09613218.2014.967977 
Lowe, R. J., Wingfield, J., Bell, M., \& Bell, J. M. 2007. Evidence for heat losses via party wall cavities in masonry construction. Building Service Engineering Research and Technology, 28(2), 161-181. doi:10.1177/0143624407077196

Majcen D, Itard L, Visscher H. 2015 Statistical model of the heating prediction gap in Dutch dwellings: relative importance of building, household and behavioural characteristics. Energy and Buildings $105: 43 e 59$.

Palmer, J. M. and Cooper, I. 2014. Great Britain's Housing Energy Fact File 2013. London: DECC.

Saunders H.D., 2015. Recent evidence for large rebound: elucidating the drivers and their implications for climate change models. Energy J 36(1):23-48. http:// dx.doi.org/10.5547/01956574.36.1.2.

Shorrock L.D., Anderson B.R., 1995. A guide to the development of BREDEM. BRE Information Paper IP 4/95, Building Research Establishment, Garston.

Shorrock L.D., Dunster J.E., 1997. The physically-based model BREHOMES and its use in deriving scenarios for the energy use and carbon dioxide emissions of the UK housing stock. Energy Policy 25:1027-1037

Sorrell S., 2015. Reducing energy demand: a review of issues, challenges and approaches. Renew Sustain Energy Rev 47:74-82. http://dx.doi.org/10.1016/

Summerfield A.J., Oreszczyn T., Palmer J, Hamilton I.G., Lowe R.J., 2015. Comparison of empirical and modelled energy performance across age-bands of three-bedroom dwellings in the UK. Energy and Buildings 109: 328-333

Summerfield A.J., Pathan A., Lowe R.J., Oreszczyn T., 2010. Changes in energy demand from lowenergy homes'. Building Research \& Information, 38:42-49

Sunikka-Blank M, Galvin R., 2012. Introducing the prebound effect: the gap between performance and actual energy consumption. Build Res Inf 40(3): 260e73. 


\section{Appendix A:}

This Appendix contains supporting data used in for the figures in the main text.

Table A1. Estimated gas consumption at the lower boundary of each EPC Band (based on SAP 2009), using mean floor areas for each dwelling type and age band from the EHS 2012.

\begin{tabular}{|c|c|c|c|c|c|c|}
\hline $\begin{array}{l}\text { Dwelling } \\
\text { Type and age }\end{array}$ & $\begin{array}{l}\text { Floor } \\
\text { Area } \\
\text { (m2) }\end{array}$ & $\begin{array}{c}\text { Band A\&B } \\
(\mathrm{SAP}=81)\end{array}$ & $\begin{array}{c}\text { Band C } \\
(S A P=65)\end{array}$ & $\begin{array}{c}\text { Band D } \\
(S A P=55)\end{array}$ & $\begin{array}{c}\text { Band E } \\
(S A P=39)\end{array}$ & $\begin{array}{c}\text { Band F } \\
(\mathrm{SAP}=21)\end{array}$ \\
\hline \multicolumn{7}{|l|}{ Detached } \\
\hline Pre 1930 & 179 & 16900 & 30300 & 45900 & 63700 & 83800 \\
\hline 1930 to 1949 & 135 & 12700 & 23600 & 36200 & 50700 & 67000 \\
\hline 1950 to 1966 & 128 & 12100 & 22500 & 34700 & 48600 & 64300 \\
\hline 1967 to 1982 & 120 & 11300 & 21400 & 33000 & 46400 & 61400 \\
\hline 1983 to 1995 & 124 & 11700 & 21900 & 33700 & 47300 & 62600 \\
\hline $\begin{array}{l}\text { Post } 1995 \\
\text { Semi- } \\
\text { detached }\end{array}$ & 143 & 13500 & 24800 & 37900 & 53000 & \\
\hline Pre 1930 & 112 & 10600 & 20100 & 31300 & 44000 & 58300 \\
\hline 1930 to 1949 & 85 & 8000 & 15900 & 25200 & & 47800 \\
\hline 1950 to 1966 & 81 & 7600 & 15300 & 24300 & 34600 & 46100 \\
\hline 1967 to 1982 & 79 & 7400 & 15100 & 24000 & 34100 & 45600 \\
\hline 1983 to 1995 & 69 & 6500 & 13500 & 21700 & 31100 & 41700 \\
\hline Post 1995 & 77 & 7300 & 14800 & 23500 & 33600 & 44800 \\
\hline \multicolumn{7}{|l|}{ End-terrace } \\
\hline Pre 1930 & 98 & 9200 & 17900 & 28000 & 39600 & 52700 \\
\hline 1930 to 1949 & 76 & 7100 & 14600 & 23300 & 33200 & 44400 \\
\hline 1950 to 1966 & 72 & 6800 & 14000 & 22500 & 32100 & 42900 \\
\hline 1967 to 1982 & 76 & 7100 & 14600 & 23300 & 33200 & 44400 \\
\hline 1983 to 1995 & 65 & 6100 & 12900 & 20800 & 29900 & 40100 \\
\hline Post 1995 & 79 & 7400 & 15000 & 23800 & 33900 & 45300 \\
\hline \multicolumn{7}{|l|}{ Mid-terrace } \\
\hline Pre 1930 & 84 & 7900 & 15800 & 25100 & 35600 & 47500 \\
\hline 1930 to 1949 & 74 & 6900 & 14200 & 22700 & 32400 & 43300 \\
\hline 1950 to 1966 & 74 & 6900 & 14200 & 22700 & 32400 & 43300 \\
\hline 1967 to 1982 & 74 & 6900 & 14200 & 22800 & 32500 & 43500 \\
\hline 1983 to 1995 & 67 & 6300 & 13200 & 21200 & 30400 & 40800 \\
\hline Post 1995 & 80 & 7500 & 15100 & 24100 & 34300 & 45700 \\
\hline
\end{tabular}


Table A2. Estimated mean gas consumption for each EPC Band (based on SAP 2009), where Bands $D$ to $G$ estimate gas consumption prior to retrofit, and Band $C$ represents the target consumption postretrofit. The SAP rating is based on the mean value in each age band obtained from EHS 2012 data.

\begin{tabular}{|c|c|c|c|c|c|c|}
\hline $\begin{array}{l}\text { Dwelling } \\
\text { Type and age }\end{array}$ & $\begin{array}{l}\text { Floor } \\
\text { Area } \\
\text { (m2) }\end{array}$ & $\begin{array}{c}\text { Band C } \\
(\mathrm{SAP}=72)\end{array}$ & $\begin{array}{l}\text { Band D } \\
(S A P=62)\end{array}$ & $\begin{array}{c}\text { Band E } \\
(S A P=49)\end{array}$ & $\begin{array}{c}\text { Band F } \\
(\mathrm{SAP}=34)\end{array}$ & $\begin{array}{c}\text { Band G } \\
(\mathrm{SAP}=12)\end{array}$ \\
\hline \multicolumn{7}{|l|}{ Detached } \\
\hline Pre 1930 & 179 & 26900 & 38100 & 52600 & 70400 & 84900 \\
\hline 1930 to 1949 & 135 & 20900 & 29900 & 41700 & 56100 & 67900 \\
\hline 1950 to 1966 & 128 & 19900 & 28600 & 39900 & 53900 & 65200 \\
\hline 1967 to 1982 & 120 & 18900 & 27200 & 38000 & 51400 & 62200 \\
\hline 1983 to 1995 & 124 & 19300 & 27800 & 38800 & 52400 & 63500 \\
\hline Post 1995 & 143 & 21900 & 31300 & 43600 & 58600 & 70900 \\
\hline \multicolumn{7}{|l|}{ Semi-detached } \\
\hline Pre 1930 & 112 & 17700 & 25700 & 36000 & 48800 & 100 \\
\hline 1930 to 1949 & 85 & 14000 & 20600 & 29200 & 39800 & 48400 \\
\hline 1950 to 1966 & 81 & 13400 & 19800 & 28100 & 38400 & 46800 \\
\hline 1967 to 1982 & 79 & 13200 & 19500 & 27800 & 38000 & 46200 \\
\hline 1983 to 1995 & 69 & 11800 & 17600 & 25300 & 34600 & 42300 \\
\hline Post 1995 & 77 & 12900 & 19200 & 27300 & 37300 & 45500 \\
\hline \multicolumn{7}{|l|}{ End-terrace } \\
\hline Pre 1930 & 98 & 15700 & 23000 & 32400 & 44000 & 53400 \\
\hline 1930 to 1949 & 76 & 12700 & 18900 & 27000 & 37000 & 45000 \\
\hline 1950 to 1966 & 72 & 12200 & 18200 & 26100 & 35700 & 43500 \\
\hline 1967 to 1982 & 76 & 12700 & 18900 & 27000 & 36900 & 45000 \\
\hline 1983 to 1995 & 65 & 11200 & 16900 & 24200 & 33300 & 40700 \\
\hline Post 1995 & 79 & 13100 & 19400 & 27600 & 37700 & 46000 \\
\hline \multicolumn{7}{|l|}{ Mid-terrace } \\
\hline Pre 1930 & 84 & 13900 & 20500 & 29000 & 39600 & 48200 \\
\hline 1930 to 1949 & 74 & 12400 & 18400 & 26300 & 36100 & 44000 \\
\hline 1950 to 1966 & & 12400 & 18400 & 26300 & 36100 & 44000 \\
\hline 1967 to 1982 & 74 & 12400 & 18500 & 26400 & 36200 & 44100 \\
\hline 1983 to 1995 & 67 & 11400 & 17200 & 24700 & 33900 & 41400 \\
\hline Post 1995 & 80 & 13200 & 19600 & 27900 & 38100 & 46400 \\
\hline
\end{tabular}


Table A3. Mean gas consumption of dwellings in NEED 2012 and estimates from two variants of the Cambridge Housing Model, (CHM(SAP) and CHM(DT19). The percentage figures refer to the prevalence of each dwelling type in that age band in the NEED dataset.

\begin{tabular}{|c|c|c|c|c|c|c|c|c|}
\hline \multirow[t]{2}{*}{ Age Band } & \multicolumn{2}{|c|}{$\begin{array}{c}\text { Detached } \\
\mathrm{N}=678,428\end{array}$} & \multicolumn{2}{|c|}{$\begin{array}{c}\text { Semi-detached } \\
N=762,830\end{array}$} & \multicolumn{2}{|c|}{$\begin{array}{c}\text { End Terrace } \\
\mathrm{N}=307,356\end{array}$} & \multicolumn{2}{|c|}{$\begin{array}{c}\text { Mid Terrace } \\
\mathrm{N}=683,703\end{array}$} \\
\hline & $(\%)$ & kWh & $(\%)$ & kWh & $(\%)$ & kWh & $(\%)$ & kWh \\
\hline \multicolumn{9}{|l|}{ NEED 2012} \\
\hline Pre-1930 & (8) & 23,256 & (15.9) & 18,105 & $(31.6)$ & 15,431 & $(50.1)$ & 13,201 \\
\hline $1930-1949$ & $(11.1)$ & 19,551 & $(30.6)$ & 15,284 & $(14.2)$ & 13,563 & $(11.5)$ & 12,336 \\
\hline $1950-1966$ & (20.3) & 15,822 & (24) & 13,470 & (15.3) & 12,325 & (11) & 11,537 \\
\hline $1967-1982$ & (27) & 15,551 & $(14.6)$ & 12,762 & (17.7) & 11,805 & $(13.6)$ & 10,677 \\
\hline 1983-1995 & (18.8) & 15,854 & (8.4) & 10,588 & (10.7) & 10,083 & (7) & 9,277 \\
\hline post-1995 & (14.7) & 16,872 & (6.6) & 11,191 & (10.5) & 11,369 & (6.7) & 10,724 \\
\hline \multicolumn{9}{|l|}{$C H M(S A P)$} \\
\hline Pre-1900 & & 44,069 & & 35,957 & & 29,340 & & 19 \\
\hline $1900-1929$ & & 37,480 & & 25,109 & & 20,832 & & 19,784 \\
\hline $1930-1949$ & & 31,275 & & 19,357 & & 15,566 & & 14,798 \\
\hline $1950-1966$ & & 26,994 & & 16,949 & & 14,875 & & 13,464 \\
\hline $1967-1975$ & & 23,816 & & 16,909 & & 15,191 & & 12,863 \\
\hline $1976-1982$ & & 21,588 & & 14,195 & & 13,146 & & 11,196 \\
\hline $1983-1990$ & & 19,536 & & 12,113 & & 11,481 & & 9,792 \\
\hline $1991-1995$ & & 22,223 & & 12,162 & & 12,788 & & 9,998 \\
\hline $1996-2002$ & & 19,669 & & 11,378 & & 11,612 & & 9,781 \\
\hline $2003-2006$ & & 20,379 & & 12,6 & & 13,064 & & 11,979 \\
\hline $2007-2011$ & & 20,680 & & & & 12,179 & & 11,407 \\
\hline \multicolumn{9}{|l|}{$C H M(D T 19)$} \\
\hline Pre-1900 & & 31,809 & & 25,900 & & 21,668 & & 16,220 \\
\hline $1900-1929$ & & 27,977 & & 19,102 & & 18,742 & & 14,868 \\
\hline $1930-1949$ & & 24,397 & & 15,440 & & 14,021 & & 11,859 \\
\hline $1950-1966$ & & 22,275 & & 14,148 & & 12,642 & & 11,339 \\
\hline $1967-1975$ & & 19,815 & & 14,191 & & 12,768 & & 10,848 \\
\hline 1976-1982 & & 18,013 & & 11,952 & & 11,057 & & 9,510 \\
\hline $1983-1990$ & & 16,326 & & 10,254 & & 9,743 & & 8,367 \\
\hline $1991-1995$ & & 18,536 & & 10,319 & & 10,802 & & 8,561 \\
\hline $1996-2002$ & & 16,418 & & 9,680 & & 9,853 & & 8,378 \\
\hline $2003-2006$ & & 16,971 & & 10,624 & & 11,003 & & 10,131 \\
\hline $2007-2011$ & & 17,224 & & 10,091 & & 10,277 & & 9,638 \\
\hline
\end{tabular}

